\title{
Is the Small Size of a Breast Cancer Tumor the Crucial Point for Successful Medical Treatment?
}

\author{
Marie Strunová1, David Pavlišta', Jitka Kobilková1, Jiří Pokorný², \\ Miloslav Janoušek ${ }^{1}$, Lenka Bauerová ${ }^{3}$,Anna Jandová ${ }^{1}$ \\ ${ }^{1}$ Department of Obstetrics and Gynaecology, First Faculty of Medicine, \\ Charles University in Prague and General University Hospital in Prague, Prague, \\ Czech Republic; \\ ${ }^{2}$ Institute of Photonics and Electronics, Academy of Sciences of the Czech Republic, \\ Prague, Czech Republic; \\ ${ }^{3}$ Institute of Pathology, First Faculty of Medicine, Charles University in Prague \\ and General University Hospital in Prague, Prague, Czech Republic
}

Received July 1, 2014; Accepted November 18, 2014.

Key words: Breast cancer - Reverse Warburg effect - Tumor aggressiveness

Abstract: The presented case displays a clinical study of a cancer phenotype with a poor clinical outcome. Prediction of cancer development and effects of treatment at the beginning of the clinical stage is difficult as the knowledge of cancer process and all necessary parameters of the host body are limited. Cancer is mainly studied on the basis of biochemical-genetic processes and their morphological manifestation. However, the malignant process is assumed to be of essential biophysical nature and develops after mitochondrial dysfunction, which is a direct result of oncogene mutation. Cancers based on the normal and the reverse Warburg effect should be distinguished. The cancer tumors with the reverse Warburg effect display aggressiveness associated with a high rate of recurrence and metastatic implantation. Besides the nature of the two basic types of breast cancer tumors the outcome depends not only on their type, size, and site but also on reactions and interaction with the surrounding tissue and the body aptitude for metastatic activity connected with individual blood or lymphatic vessels for metastatic transport. It is necessary to assess all favourable and adverse factors for cancer development. General reliable method of their specification for all cancers

Mailing Address: Prof. Jitka Kobilková, MD., DSc., Department of Obstetrics and Gynaecology, First Faculty of Medicine, Charles University in Prague and General University Hospital in Prague, Apolinářská 18, 12851 Prague 2, Czech Republic; e-mail: jitka.kobilkova@centrum.cz 
is not available. Nevertheless, the main factor seems to be aggressiveness of cancer cells as follows from interpretation. To reveal the aggressive reverse Warburg effect tumors, metabolic biomarkers of the fibroblast stress should be examined.

\section{Introduction}

Breast cancer is the most frequent malignant tumor in Czech women. In the year 2011 the incidence of breast cancer (per 100000 women evaluated for the whole Czech Republic) was 33.2. It is presupposed that the small size of breast cancer gives hope for the women and high expectation for their successful treatment. If used, the advantage of optimal secure remedy after surgery and health expectancy is in high percentages. The patients treated and followed up in the centres for gynaecological and oncology prevention, who had breast cancer at the time of post menopause and at the old age had better treatment results than those in youthfulness. We have compared the clinical symptoms, the results of the laboratory examinations to find the cause why the small size breast cancer in a 49-year-old woman had taken the bad course. The patient did not survive 4 years although she had the best surveillance and all available up-to-date treatment.

\section{Case report}

The description concerns a woman, born in the year 1960, mother of 2 children (both were breastfed by their mother). She was taking hormonal contraception, started from the end of the childbed continuously up to the time, when the chemotherapy stopped the menstrual bleeding. Two years before the breast cancer diagnosis, the patient had the uterus cavity scraped up (curettage) due to strong uterus bleeding. The histology finding revealed endometrium hyperproliferation, partly polyposis. At the end of the year 2009, a tumor of about $2 \mathrm{~cm}$ size was removed from the right breast of the woman. The histology result was: invasive ductal cancer. The chemotherapy followed the surgery, i.e. AC-TH. After six month the medical consultation advised to perform right mastectomy together with the right axilla exenteration, as the tumor displayed multifactorial features in the control mammography picture. The histology confirmed invasive breast cancer of G3 grading, ER (oestrogen) receptors were 30\%, PG (progesterone) receptors were negative, erb $80 \%$ and FISH +. The axillary lymphatic nods were without any malignancy. The laboratory examination results were as follows: Her $2 /$ neu (c-erb B-2) with certified VENTANA Her 2/neu according to the method SOP-PATH 09. The Herceptin monotherapy of one year duration was recommended by oncologists. In the end of the year 2011, the woman complained of bone pains without any specification. Therefore, Coxtral $100 \mathrm{mg}+$ NOB $100 \mathrm{mg}$ medication was started. On February 2, 2012 the bone and lung founded metastatic deposits were examined. According to the medical consultation, the Plaxitacel in combination with Herceptin were prescribed. A month later 3 new metastases in brain were revealed and done away by means of a gamma knife. Up to this time 
the woman was not treated by Xeloda and Tyverb. The oncologists recommended starting with the palliative therapy by Xeloda and Tyverb. Spinal pains were a little damped down by analgesic irradiation. On April 11, 2013 the woman had asthmatic breathing without any corporal movements. The $\mathrm{X}$-ray picture showed conspicuous shadow in the lateral chest wall of an uncertain cause. At the same time the woman noticed a swollen part of the mastectomy scar. The mammography revealed a shadow of $13 \mathrm{~mm}$ of uncertain bounds. The patient insisted on the removal of the swollen scar part. The histopathologist description of the scar excision was as follow: "The tissue excision is covered by skin with multiple marks of healing. Under the skin covering there are marked signs of infiltration by solid arranged invasive ductal cancer of $\mathrm{G} 3$ grading. The cancer cells extend to the desmoplastic stromal tissue which does not reach up to the resection board. The cancer cells invade blood and lymphatic vessels." ER and PG receptors were negative MiB (ki67) $40 \%$, Her $2 /$ neu $3+$ (c-erb-B-2). The examinations were conducted according to certified kit VENTANA Her 2/neu by the method SOP-PATH-09. On July 18, 2013 the woman was admitted at the oncology department due to breathing difficulties as she had pleural exudation of the amount of 1,600 ml, Crp 196, $\mathrm{Na} \mathrm{13,} \mathrm{Cl} \mathrm{94,}$ leucocytes 23.5, Er 3.52, Hbc 104, HTc 0.31. Exitus letalis on July 23, 2013.

\section{Discussion}

Aggressiveness of the breast cancer tumor, the extremely running course, and its resistance to the chemotherapy correspond to behavior of the tumor type of the reverse Warburg effect. The Warburg effect was discovered ninety years ago (Warburg et al., 1924; Warburg, 1956). In contrast to the classical understanding of the Warburg effect, the reverse Warburg effect is characterized by functional mitochondria in the cancer cell and dysfunctional mitochondria in its associated fibroblasts (Pavlides et al., 2009). Enormous malign activity depends on the autophagic tumor stroma around the cancer cell. The stromal cells exposed to the oxidative stress produce pyruvate, ketons and other metabolites which fuel oxidative metabolism in cancer cell (Pavlides et al., 2009; Sotgia et al., 2012; Witkiewicz et al., 2012). A predictive biomarker of this event is the loss of stromal caveolin-1 (Cav-1) associated with a high rate of tumor recurrence, metastatic process and tamoxifen resistance. However, the woman reported was not examined to prove or disprove the cancer type of the reverse Warburg effect.

The most prominent metabolites found by Pavlides et al. (2010) are asymmetric dimethylarginine and beta-hydroxybutyrate (and some other keton bodies) which are markers of the oxidative stress and mitochondrial dysfunction, respectively. They were revealed in aggressive breast cancer patients in plasma and also in excised tumor tissue. So it would be very useful for the treatment strategy and/or for evaluation of the treatment efficacy to identify the biomarkers of the oxidative stress and to determine the group of women, candidates for aggressive breast cancer course. Cav-1 has an important role in the physiological wound healing. 
It is known that activated fibroblasts generated via mediated differentiation of normal fibroblasts are the basis for physiological healing of the wounds. The loss of Cav-1 leads to the fatal disorder in the fibroblast compartment which restrains the healing process and enables the tumor recurrence, metastases, and bad clinical outcome (Schafer and Werner, 2008). The loss of Cav-1 may be assumed to be a synonym for the poorly differentiated cancer cells of the patient reported. The absence of stromal Cav-1 expression has on the other hand the most predictive value which is independent of the epithelial marker status of all subclasses of breast cancers including $\mathrm{Er}^{+}, \mathrm{Pg}^{+}, \mathrm{Her2}^{+}$, and triple-negative patients $\left(\mathrm{Er}^{-} / \mathrm{Pg}^{-} / \mathrm{Her}^{-}\right)$ (Pavlides et al., 2009).

There is one more factor which contributes to the aggressiveness of the breast cancer behaviour. Research evaluations indicate that the clinical phase of a cancer tumor seems to be demarcated in one site but the malignant cells could invade

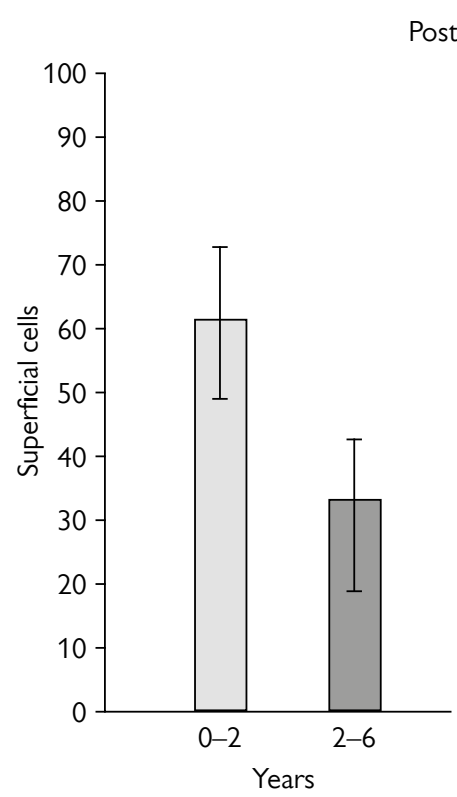

Postmenopausal age

Senium
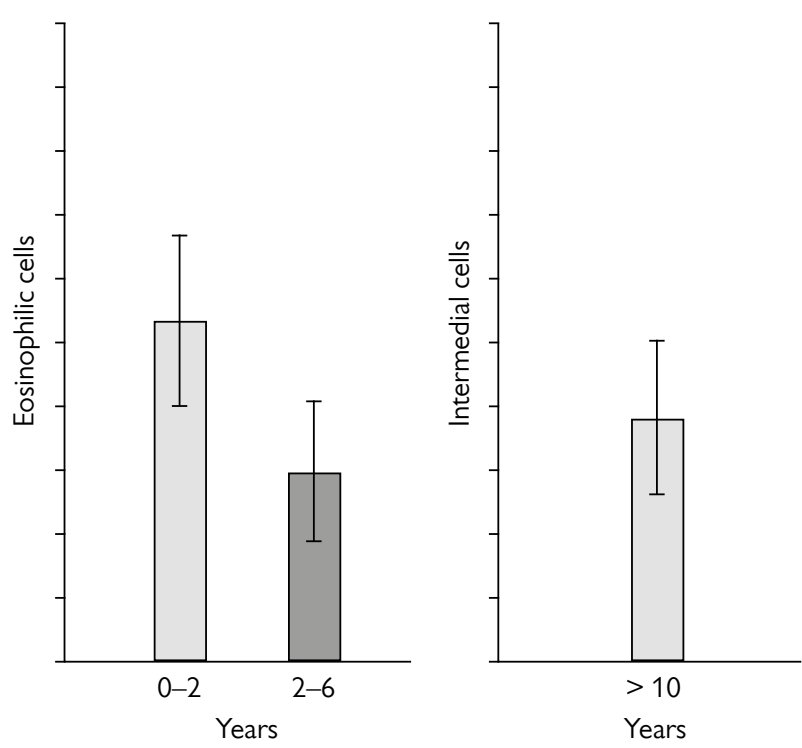

Figure 1 -The number of superficial (both eosinophilic and cyanophilic), eosinophilic, and intermedial cells (in \%) displaying hormonal cytology findings of the oestrogen level which promotes development of the breast cancer in women at the age of postmenopause and in the senium. The group of 227 patients was examined by cytology pictures. Women with the breast cancer followed by hormonal cytodiagnostics whose data were measured in the two periods (up to 2 and from 2 to 6 years after the last menstruation) during the menopausal age, and in senium (10 years after the menopause and later). The level of the karyopyknotic index (\% of superficial cells) and of the eosinophilic index (\% of eosinophilic cells) gives evidence for unusual oestrogen activity corresponding to values of the nomograms of the Czech young women (Kobilková, 1967; Kobilková et al., 1977). In the senium the vaginal physiological hormonal cytology smears show the atrophy (in healthy women the indices of the oestrogen level are at zero). $40 \%$ of intermedial cells are considered as proliferation activity of the body tissues. 
the blood and lymphatic vessels, which brought them into distant organs of the body. In our patient the special examinations demonstrated the quickly arising metastatic centres far from the primary cancer site. The short time needed for cancer spread could be explained by Pavlišta and Eliška findings $(2005,2012)$. In some women there exist connecting vessel ways from one arm pit to the other one. In addition, the oestrogen hyperstimulation leads to undesirable proliferation (Kobilková et al., 1977). The breast changes, such as differentiation, growth, and involution are closely connected to the endocrine activity. The hormonal level in women suffering from breast cancer in the postmenopausal period and in the elderly was investigated. According to the cytology findings the hormonal balance disorder is connected with oestrogens, which support proliferation in body tissues. (Experimental data on oestrogen level that affects the breast cancer in women are in Figure 1.) In the woman reported, there were signs of excessive oestrogenic activity 2 years before the breast cancer was revealed as the histology from the uterus city scrap gives evidence for non-appropriate oestrogenic stimulation. In the patients with the higher BMI (body mass index) precancerous lesions in the cervix are more frequent than in the patients having lower BMI. The higher BMI was associated with increased serum oestradiol levels (Ahn et al., 2012). It is evident that hormonal alteration - higher oestrogenic stimulation can affect the outcome of the breast cancer markedly. In the case reported the patient had $10 \mathrm{~kg}$ over the BMI specifications. The other question is an extremely long time of hormonal contraception using a remedy containing the oestrogen component. Histological differences between primary tumor and the metastases in our patient also depend on their milieus. Various viruses also play an important role in cell cancer transformation. Cancer is a very remarkable genetic heterogeneous entity and the most powerful among all illnesses (Slezák, 2013).

Aggressiveness and generalization of the cancer tumor at its early clinical stage have to be connected with its internal mechanism. Cancer attacks the essential mechanisms and processes of life connected with energy supply (Pokorný et al.,

\section{Table 1 - Favourable and adverse factors in malignancy of the women examined for breast cancer}

\begin{tabular}{ll}
\hline Favourable factors & Adverse factors \\
\hline Breast feeding of both children & Over weight (BMI) high \\
\hline $\begin{array}{l}\text { Cancer occurrence } \\
\text { at the end of climax }\end{array}$ & $\begin{array}{l}\text { Using hormonal contraceptives from childbed up } \\
\text { to the chemotherapy start }\end{array}$ \\
\hline Small tumor size of about $2 \mathrm{~cm}$ & $\begin{array}{l}\text { Oestrogens proliferation activity demonstrated in the } \\
\text { endometrial tissue (polyposis and hyper proliferation) }\end{array}$ \\
\hline Weakly differentiated primary cancer (G3) \\
\hline Adverse factors predominate!
\end{tabular}

Strunová M.; Pavlišta D.; Kobilková J.; Pokorný J.; Janoušek M.; Bauerová L.; Jandová A. 
2013a). Cancer cells with the reverse Warburg effect have higher oxidative metabolism and should have a higher electromagnetic activity than healthy cells. Local invasion and metastases driven by attractive and repulsive interactions between cells are connected with the generated electromagnetic field (Pokorný et al., 2012, 2013a, b). The frequencies of the electromagnetic fields of cancer cell and its associated fibroblasts are shifted in opposite directions in the initial phase of malignant transformation after induction of the mitochondrial dysfunction in fibroblasts. Consequently, the repulsive interactions appear in the early stage of tumor development. It is also necessary to assess all factors favourable and adverse to cancer therapy options (Table 1). A new way of therapy should target the mitochondrial dysfunction, a central point of cancer, which is formed after abrogation of oncogene-induced senescence (Kaplon et al., 2013). It is hoped, that restoration of the functional state of mitochondria and their effect on microtubules in cancer cells or fibroblasts associated with the cancer cell will bring a new possibility of cancer treatment (Pokorný et al., 2013a).

\section{Conclusion}

1. A small size of a cancer tumor cannot be a favourable sign on its own for a good patient outcome. It is evident that two types of breast (but not only of breast) cancer exist and that they are of different clinical outcome. The most dangerous for human life is the cancer of the type of the reverse Warburg effect.

2. The behaviour and structure of the tumor metastasis from the primary cancer site can be diverse due to proliferation reaction possibility of the surrounding tissue. The oestrogenic proliferation activity of the body tissues influences the rapid tumor progress. The summary of the favourable and adverse factors connected with cancer process development such as obesity and immoderate proliferation activity should be taken into account for judgement of therapy choice by clinicians.

3. For treatment judgement and stratification, the identification of the basic markers of mitochondrial dysfunction is fundamental. Asymmetric dimethylarginin, betahydroxybutyrate ketone body, and Cav-1 should be determined from serum examination, performed directly on the excised tumor tissue or the tissue acquired by Punch biopsy.

\section{References}

Ahn, S., Lee, Y.-Y., Sung, J.-Y., Lee, J. J., Oh, Y. L., Sung, C. O., Song, S. Y. (2012) Body mass index and outcome of ASC-H-interpreted cervical smears in postmenopausal women. Acta Cytol. 56(3), 259-265.

Kaplon, J., Zheng, L., Meissl, K., Chaneton, B., Serlivanov, V. A., Mackay, G., van der Burg, S. H., Verdegaal, E. M. E., Cascante, M., Shlomi, T., Gottlieb, E., Peeper, D. S. (2013) A key role for mitochondrial gatekeeper pyruvate dehydrogenase in oncogene-induced senescence. Nature 498, 109-112.

Kobilková, J. (1967) Cytological study of the level of estrogen during the reproductive age. Acta Cytol. 11, 497-512. 
Kobilková, J., Filipovičová, M., Papež, L., Kvapil, F. (1977) Zytologische Bilder der hormonalen Situation bei Frauen mit Brustdrussentumoren. Arch. Geschwulstforsch. 47(7), 641-648.

Pavlides, S., Whitaker-Menezes, D., Castello-Cros, R., Flomenberg, N., Witkiewicz, A. K., Frank, P. G., Casimiro, M. C., Wang, C., Fortina, P., Addya, S., Pestell, R. G., Martinez-Outschoorn, U. E., Sotgia, F., Lisanti, M. P. (2009) Reverse Warburg effect. Aerobic glycolysis and cancer associated fibroblasts and their tumor stroma. Cell Cycle 8(23), 3984-4001.

Pavlides, S., Tsirigos, A., Migneco, G., Whitaker-Menezes, D., Chiavarina, B., Flomenberg, N., Frank, P. G., Casimiro, M. C., Wang, C., Pestell, R. G., Martinez-Outschoorn, U. E., Howell, A., Sotgia, F., Lisanti, M. P. (2010) The autophagic tumor stroma model of cancer. Role of oxidative stress and ketone production in fuelling tumor cell metabolism. Cell Cycle 9(17), 3485-3505.

Pavlišta, D., Eliška, O. (2005) Cutaneus and subcutaneous lymphatic drainage of the breast. Lymphology 38(2), 92-102.

Pavlišta, D., Eliška, O. (2012) Relationship between the lymphatic drainage of the breast and upper extremity. A post mortem study. Ann. Surg. Oncol. 19(11), 3410-3415.

Pokorný, J., Jandová, A., Nedbalová, M., Jelínek, F., Cifra, M., Kučera, O., Havelka, D., Vrba, J., Vrba, J. Jr., Čoček, A., Kobilková, J. (2012) Mitochondrial metabolism - Neglected link of cancer transformation and treatment. Prague Med. Rep. 113(2), 81-94.

Pokorný, J., Foletti, A., Kobilková, J., Jandová, A., Vrba, J., Vrba, J. Jr., Nedbalová, M., Čoček, A., Danani, A., Tuszynski, J.A. (2013a) Biophysical insight into cancer transformation and treatment. Scientific World Journal 2013, doi:10.1155/2013/195028.

Pokorný, J., Pokorný, J. Jr., Kobilková, J. (2013b) Postulates on electromagnetic activity in biological systems and cancer. Integr. Biol. (Camb.) 5(12), 1439-1446.

Schafer, M., Werner, S. (2008) Cancer as an overhealing wound an old hypothesis revised. Nat. Rev. Mol. Cell Biol. 9, 628-638.

Slezák, M. (2013) Fighting cancer Darwin's way. Evolutionary medicine. New Sci. 7, 12-19.

Sotgia, F., Whitaker-Menezes, D., Martinez-Outschoorn, U. E., Flomenberg, N., Birbe, R. C., Witkiewicz, A. K., Howell, A., Philp, N. J., Pestell, R. G., Lisanti, M. P. (2012) Mitochondrial metabolism in cancer metastasis. Visualizing tumor cell mitochondria and the "reverse Warburg effect" in positive lymph node tissue. Cell Cycle 11, 1445-1454.

Warburg, O. (1956) On the origin of cancer cells. Science 123, 309-314.

Warburg, O., Posener, K., Negelein, E. (1924) Über den Stoffwechsel der Carcinomzelle. Biochem. Z. 152, 309-344. (in German)

Witkiewicz, A. K., Whitaker-Menezes, D., Dasgupta, A., Philp, N. J., Lin, Z., Gandara, R., Sneddon, S., Martinez-Outschoorn, U. E., Sotgia, F., Lisanti, M. P. (2012) Using the "reverse Warburg effect" to identify high-risk breast cancer patients. Stromal MCT4 predicts poor clinical outcome in triple-negative breast cancers. Cell Cycle 11, 1108-1117.

Strunová M.; Pavlišta D.; Kobilková J.; Pokorný J.; Janoušek M.; Bauerová L.; Jandová A. 